\title{
Using IT to Improve Communication between Boundaries of Organizations: Case Studies in Japanese Companies
}

\author{
Sho Hanaoka \\ Kanto Gakuin University, \\ Japan \\ hanaoka@peach.ocn.ne.ip
}

\author{
Tatsumi Shimada \\ Tokyo Metropolitan Institute of \\ Technology, Japan \\ tshimada@cc.tmit.ac.jp
}

\begin{abstract}
Most Japanese companies are facing difficulties caused from a long term recession of Japanese economy, plagued with such questions as how to accelerate decision making process, how to make proper judgments in decision, and how to predict the future trends of concerned industry, etc. There are two main causes of these difficulties now facing most Japanese companies using the traditional so-called "Japanese management style." The first notable characteristic is the "middle up down" decision-making process, which is supported by mutual consent of all belongings to numerous groups or organizations in the same company. The second is each group or organization has its own peculiar knowledge tacit to them, called "tacit knowledge." The pressing need for most Japanese companies is to quicken the decision-making process by furthering the advantages and reassessing the disadvantages of gaining access to knowledge or information of each or organization. In this paper, first, we clarified the basic structure of the traditional decision-making process in Japan. Then second, we described the mechanism of sharing information across the groups or organizations each having its own boundary. Finally, we discussed the use of IT to cross the boundary of groups to effectively to quicken and to share communications in the decision-making process in the future of Japanese industries.
\end{abstract}

Key words: information sharing, decision making process, tacit knowledge, organization culture

\section{Introduction}

There are many outstanding researches on the Japanese management. For examples, Yoshino (1968) pointed out the typical Japanese decision making system based on consultation by means of a circular. In this case, in lieu of a meeting a circular is sent around to obtain approval of a decision. In addition, Ouchi (1981) proposed an ideal model for an organization named $\mathrm{Z}$ type in which we can find merits of both American and Japanese style management. Vogel $(1976,1984)$ suggested that the merits consisted of loyalty to the enterprise, to which the employee belonged to and sensed certain togetherness among each employee.

In summary, the results of various preceding researches about the Japanese management can be summarized as lifetime employment, a consultation system via circular in lieu

Material published as part of this proceedings, either on-line or in print, is copyrighted by the author with permission granted to the publisher of Informing Science for this printing. Permission to make digital or paper copy of part or all of these works for personal or classroom use is granted without fee provided that the copies are not made or distributed for profit or commercial advantage AND that copies 1) bear this notice in full and 2) give the full citation on the first page. It is permissible to abstract these works so long as credit is given. To copy in all other cases or to republish or to post on a server or to redistribute to lists requires specific permission from the author. of meeting, a pay scale based on seniority, etc. However, these systems have had to undergo change in recent years in response to the recession of Japanese economy. Nevertheless, the essential model of traditional Japanese behavior seems to still thrive in certain areas. Therefore, we must examine what lies behind the outward form to grasp the inner meaning of these phenomena, which require change and those that do not.

From these points of view, the main objectives of our study are to clarify the following points.

- The structure of decision-making process peculiarly unique to Japanese companies.

- The process or dynamics of information sharing across the boundary of organizations.

Finally, we propose an effective implementation of information technology (hereafter IT) to facilitate communication between groups and organizations. 


\section{Using IT to Improve Communication}

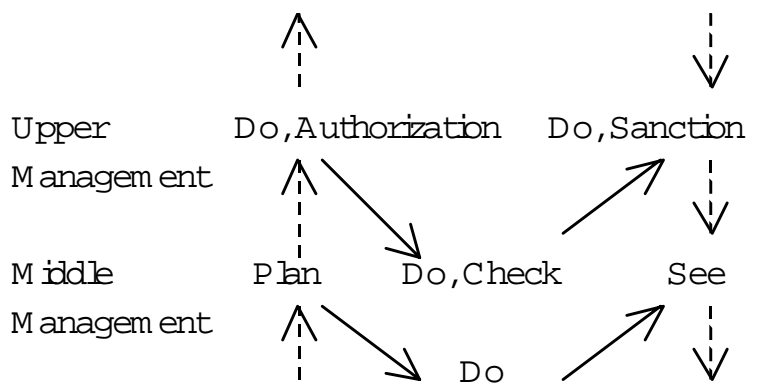

Figure 1. Hijikata's "Middle up down" Systems (Traditional Japanese decision making process).

\section{Management Style and Information Sharing}

\section{"Middle up down" Systems}

Hijikata (1968) proposed a model of Japanese management cycle known as "middle up down" systems. (See Figure 1.)

He emphasized that, in most cases in Japanese companies, the Plan-Do-See management cycle does not work smoothly, because management cannot decide organizational policy arbitrarily. He obligated to ask opinions from his subordinate before making decisions because there is no clears division of duties between superior and followers. Sometimes the decision making process becomes confused in the ambiguities.

Before making plans, management will collect adequate information and discuss exhaustively with his subordinates. In most case, negotiations aimed at reaching a consensus are already underway behind the scenes. Thus, in the next phase, the plan will be authorized by all.

\section{Organization as a Castle}

In most cases, a management will not form decision alone. It will be formed via several steps and at all levels within the company. Consequently, the peculiarity of Japanese decision-making process is a process of shared representative system based on a circular sent around to insure getting approval by all on decision. In another words, each level or group activity places a check on the directions at another level or group. Thus, all members within a group show a closely united decision. After long discussion, members all feel assured of togetherness, such as in-group or we-group in contrast to other-group or out-group. Considering the circumstances mentioned above, each group within a company resembles a "Castle" or walled-in city enclosed by a high wall or "border".
In summary in order to make any appropriate decision, it is always necessary to develop better communication with other groups or members. Related information must circulate smoothly across the boundary.

\section{Explicit Knowledge}

Next Nonaka (1995) emphasized that one of the important factors of a predominant Japanese company is a groupknowledge generating systems. After precise analysis of Japanese companies, he found four types of knowledge conversion mode, namely, socialization, externalization, combination and internalization.

In the first conversion phase, sharing each experiences and skill take place between each other and form a common mental model that generates tacit knowledge. In the externalization phase, the tacit knowledge will convert to explicit knowledge under a clear concept of the organizational process. Then, in the combination phase, each piece of explicit knowledge will combined each other and forms a new explicit knowledge system. Finally, in the internalization phase, the explicit knowledge is unified with the existing tacit knowledge through learning process by doing.

\section{Characteristics of Information}

According to Imai (1984), there are two types of information. The first type named "Information A" (hereafter, Type A) is syntax-oriented type of information that attaches greater importance to its formality than its meaning or contents. The second type named "Information B" (hereafter, Type B) is semantic-oriented type of information that attaches greater importance to its meaning or contents itself than its formality.

The Type A is characterized by a standardization of its format and a consistency of its processing, whereas Type B is characterized by diversification of its format and ad hoc processing. Computer can easily process most kinds of Type A, while it is difficult to process Type B by computer. We can express most of explicit knowledge by combining it with Type A, while Type B enables it to express most kinds of tacit knowledge.

\section{Knowledge in a Castle}

We can make clear the Japanese decision making process by applying Hijikata's "Middle up down" and "Castle" models. In addition, the group knowledge generating system can be made clear by applying Nonaka's model. Meanwhile, there are the dynamics of cooperation and opposition occurring between groups or organizations simultaneously, because each group or organization acts like a 


\section{Hanaoka and Shimada}

castle having its own set of tacit and implicit knowledge. Nevertheless, there are common objectives and goals between each of the set of information. In addition, there are common tacit and explicit knowledge within the company's own organizational culture.

\section{Hierarchy of Castles}

According to the Hijikata's model, the structure of organization is expressed as "a pile" of small castles. In another words, small castles are stacked both in horizontal and vertical directions of the organization. Each of the castles has its own in-group culture despite the fact that there is a common organizational culture --i.e. corporate identity.

The majority of group members feel a certain sense of closeness when they adapt themselves to their surroundings and pledge their loyalty to their group. As a result, they are tend to think only of their group's own convenience in way of doing things as long as their interests do not conflict. For example, they often keep information secret within their group, no matter if their action may go against the policies of public welfare. Thus, they keep the inexpedient information inclusive within each castle. However, once their group's interests conflict, they suddenly turn whistle blowers and secret information will flow out to the outside.

\section{Applying Hierarchy Model}

Tapscott (1995) classified organizational hierarchy into five levels, which includes high performance team (level 1), integrated organization (level 2) and extended enterprises (level 3). (Tapscott suggested that there have been the following moves: Business process re-design (level 1), Organizational transformation (level 2) and Re-casting ex- ternal relationships (Level 3))

Thus Tapscott's three level hierarchy will also express the hierarchy of castles in ordinary Japanese companies. Figure 2 shows the concept of organizational hierarchy. Each rectangular in Figure 2 indicates Hijikata's Castle surrounded by walls. The center part indicates a firm integrated by high performance its teams (B stands for Business in Figure 2). "Extended Enterprise" will realize by mutual communication between businesses (B to B). The main flow of information takes two directions i.e., vertical flow and horizontal flow. There are two types of information, Type A and Type B. Most kinds of Type A flow periodically to and from both directions in $\mathrm{B}$, and in horizontal directions, $\mathrm{B}$ to $\mathrm{B}$, in accordance with predetermined procedures. These flows closely related with the knowledge explicitly generated. Most kinds of Type B flows by following ad hoc operations to and from both directions in B, which closely relate with generating tacit knowledge of individual castle. Some information of Type B is intentionally concealed within a castle, but sometimes it is leaked out intentionally.

\section{Structure of Network}

We can define the structure of information network as a chain of information- conductors, which cross the boundaries between each castle. Information will sometimes be refracted, reflected and diffused when information pass through a boundary of organizations. Figure 3 shows the behavior of information across a boundary simulating by incident light, diffused reflection, etc. In Figure 3, Oa and $\mathrm{Ob}$ stands for organization $\mathrm{A}$ and organization $\mathrm{B}$ respectively. There is a boundary between $\mathrm{Oa}$ and $\mathrm{Ob}$. Incident information comes from $\mathrm{Oa}$ and enters into Ob. Sometimes, a part of incident information will be reflected (or

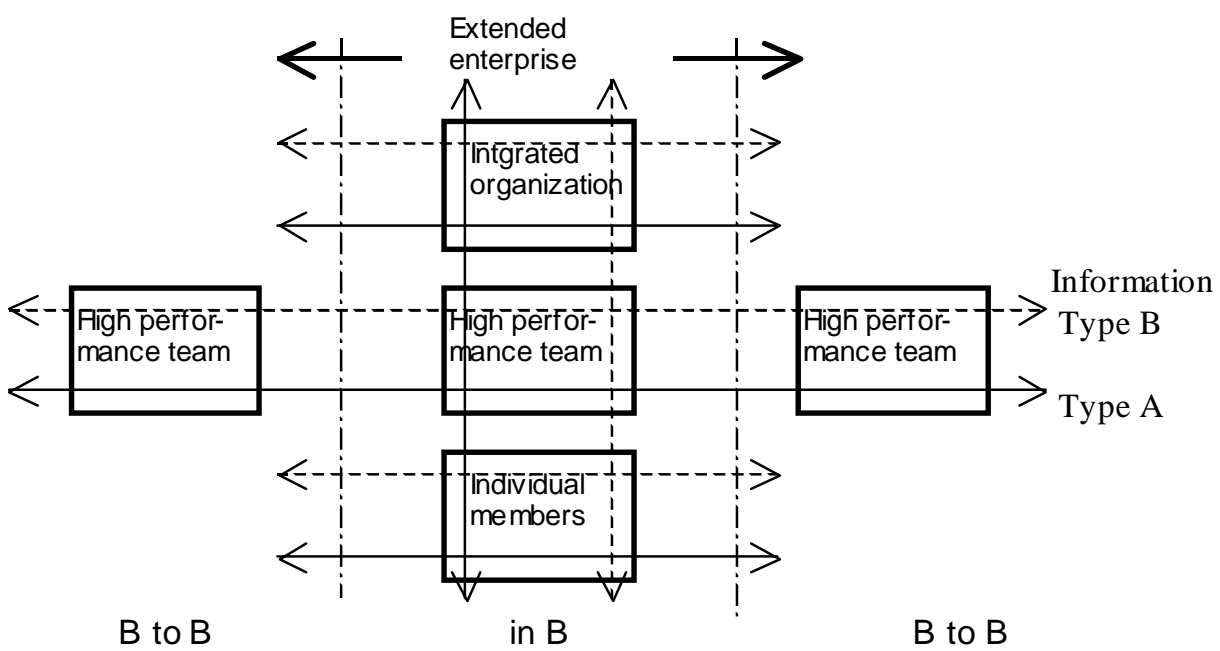

Figure 2 Hierarchy of Castles 


\section{Using IT to Improve Communication}

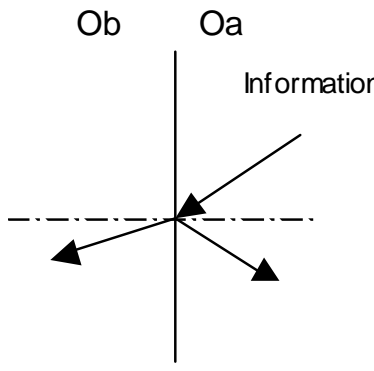

(a) refraction

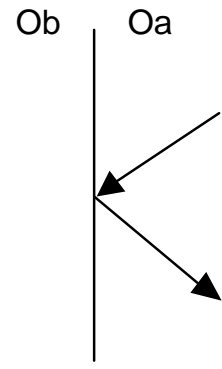

(b)reflection

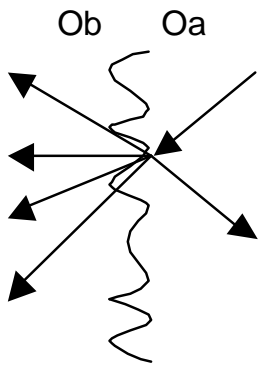

(c)diffused refraction

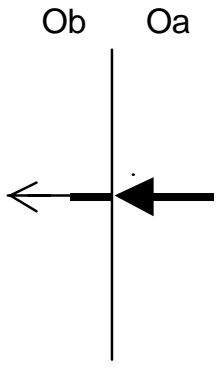

(d)attenuation

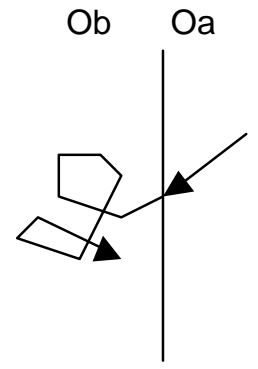

(e)disturbance

Figure 3. Information across the Boundary of Organizations

rejected) at the surface of $\mathrm{Ob}$, and another part will be introduced into $\mathrm{Ob}$ (Figure 3 (a)). The angles of reflection differ by interest. If interests conflict between $\mathrm{Oa}$ and $\mathrm{Ob}$, entire information will reflect. The surface becomes a reflector (Figure 3 (b)). If the relationships between $\mathrm{Oa}$ and $\mathrm{Ob}$ fluctuate, it ripples through the boundary surface. Information will diffuse (Figure 3 (c)). If there is a lack of communication within $\mathrm{Ob}$, refracted information will attenuated. If $\mathrm{Oa}$ is in confusion, information will be disturbed (Figure 3 (e)).

\section{Boundary Conditions}

If adjacent organizations are characterized by homogeneity without any awareness between them, the boundary becomes insignificant. These organizations can share entire necessary information with each other. However, in fact, each castle has its own culture and interest. Sometimes conflicts occur between them. As a result, inconvenient inside information will kept in secret even if this secrecy goes against the total advantage of the company. Bignell (1984) said in order to avoid systems failure; it is essential to develop better communication between the other members. There are four elements for realizing better communication. They are,

- (1) Sender of information,

- (2) Exact information,

- (3) Information channel

- (4) Receiver.

A sender must observe his objectives with great interest. Information must be proper, timely and accurate. Information cannel must be low-priced although having enough capacity and not distort information. A receiver of information must actually exist and able to comprehend informa- tion. In addition, receiver must take action according to the received information.

Viewing the boundary conditions of Figure 3, sender belongs to $\mathrm{Oa}$ and receiver belongs to $\mathrm{Ob}$. By applying Bignell's four elements, we can explain refraction of proper information and reflectance of useless information. We can also explain the characteristics of channel by the boundary conditions between $\mathrm{Oa}$ and $\mathrm{Ob}$. If the boundary swings, information diffused at the surface.

We can explain the behavior of Type A information by applying Bignell's model. While type B, it seems difficult to analyze in details. For examples, attenuation and disturbance in each medium cannot explain only by applying Bignell's model, because the characteristics of each medium reflect own organization culture. As for Japanese companies, they have own organizational culture, such as lifetime employment, middle up down management style, etc. Attenuation and disturbance of information also vary by organizational culture and effectiveness of information systems.

\section{Fluctuation of Boundary}

There are many causes for fluctuation of boundary. Any organization must have its own core competence. However, core will transform by keeping up with the change of surrounding conditions such as competition, pressure from abroad, rise and fall in the exchange rate, economic conditions, etc. An unexpected sudden change of surrounding condition will bring about serious fluctuation of boundary. As a result, fluctuation diffuses, attenuates and disturbs the information in $\mathrm{Ob}$.

According to Hijikata's model, above mentioned, there are distinct "middle up down systems" in Japanese companies. 


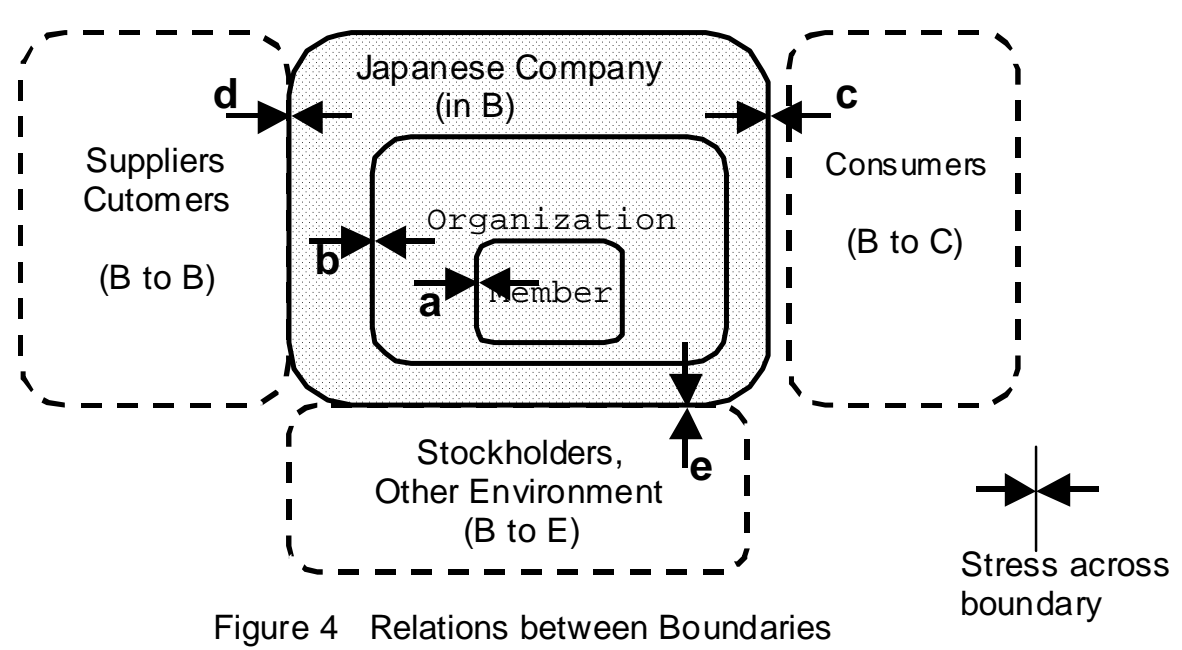

This system becomes confused by the fluctuation of boundary.

\section{Type $A$ and Type B Information}

Behavior of information differs by its type. Type A information will not diffused or distorted compare with Type B, because standardized processes of repetitive operations of business process generate the majority of Type A information. Generally, these operations are computerized. While the behavior of Type B information differ greatly by the difference of own tacit knowledge of the organization.

\section{Stresses across Boundary}

\section{Applying Porter's Model; B to B, B to C}

Figure 4 shows the hierarchal structure of castles in typical Japanese companies. The minimum components are individual members. They are members of high performance team or organization. The team is also a component of integrated organization, i.e., a Japanese company. There are walls along with each boundary of castles. Every component exists under the stress caused from internal conditions of organization itself and caused from boundaries. Viewing from the Porter and Millar models (1985), there are five forces surrounding a company. They are bargain power of suppliers, threat of new entrants, threat of substitute products or service, bargaining powers of buyers and rivalry amongst existing competitors. The arrows surrounding company in Figure 4 show these five forces, which are expressed as stress between "B to B," "B to C" and "B to E." The location of each boundary remains along the balanced of stress from outside and stress from inside. If balanced line moves, the boundary moves until the both stress maintain the balance of power.

\section{Stress in B}

Each organization has its own advantages and disadvantages in regards to the surrounding organizations even though belonging to the same company and sharing equal objectives. For examples, they compete against each other to obtain more personnel, more budgets, less share of responsibility. This phenomena appears be more serious in Japanese companies than other countries, because the majority of employees stay a long period in the same company.

They inwardly desire a stable post and job situation; "Don't object to the policy now. This isn't the time to cause waves."

They are afraid of being left out the group and excluded from the norm of the company, because most seek employment, though uneventful as long as it is comfortable in their lifetime in the same circumstances. Some never go out of their way to do anything and merely want to avoid complications.

They often intend to hide improper or troublesome actions or results until the matters blow over. A terrible fact will become to light when they cannot hide it by themselves. Sometimes, they expose a situation from within when their smoldering resentment burst into frame. The threshold level will fluctuate by whether they have proper information or not. Thus, the problem becomes more serious and a method of settlement is also confused. 


\section{Case Studies}

\section{Cases on Ethics Problems}

We can find typical characteristics of Japanese companies in the following cases cited from the recent issues of Nihon Keizai Shimbun (a high quality business newspaper in Japan, hereafter Nikkei) from May to October 2000.

\section{Case 1: M Electric (Electric Machinery Manufac- turer)}

M Electric is the third largest general electrical machinery manufacturer in Japan having about 43,000 employees. The annual consolidated sales in $1999 \mathrm{FY}$ consisted of about 3,770 billion Yen. In the middle of September 2000, newspapers discovered the secret that, about ten years prior, some components of a certain type television sets made by M Electric burned out, which M Electric tried to conceal the fact. However, the chief executive officers of M Electric knew nothing about the fact, because the division management tried to conceal it for the sake of selfprotection.

\section{Case 2: M Motors (Motor Car Manufacture)}

$\mathrm{M}$ Motors is the fourth largest motorcar manufacture in Japan having about 22,700 employees. The annual consolidated sales in 1999 FY were about 3,550 billion yen. They tried to conceal the complaint reports in employee's lockers even if coming from defective car users. Sometimes, the hidden reports has serious problems that required a report to the authorities. Top management participated in this illegal action.

\section{Case 3: Y Products (Dairy Products Maker)}

Y Products is the largest maker of butter, cheese, etc. in Japan having about 6,700 employees. The consolidated annual sales in $1999 \mathrm{FY}$ amounted to about 1,290 billion Yen. In July 2000, there was large-scale food poisoning by the low fat milk made by Y Products. The source of the trouble was their skimped manufacturing process that came from their overconfidence.

\section{Cases on B-to-B Collaboration}

Recently, we can often find "B to B" cases collaborated beyond the affiliated companies, focusing to strengthen the competitiveness within their business field. Following cases cited from Nikkei issued from May to October 2000.

\section{Case 4: Cooperation between Nihon Life Insur- ance, Mitsui Life Insurance and Sumitomo Mari- time Insurance}

Nihon Life Insurance is the largest life insurance company. Mitsui Life Insurance belongs to the Mitsui Financial Group one of the largest "zaibatsu" (A tight business combine) in Japan. Sumitomo Maritime Insurance belongs to the fourth largest maritime fire insurance company belonging to the Sumitomo Financial Group.

Beyond their groups, these companies are planning to cooperate with each other by supplying competitive merchandises. In addition, their information systems will be standardized in order to eliminate IS cost.

\section{Case 5: Alliance between Sakura Bank and Mitsui Marine Insurance}

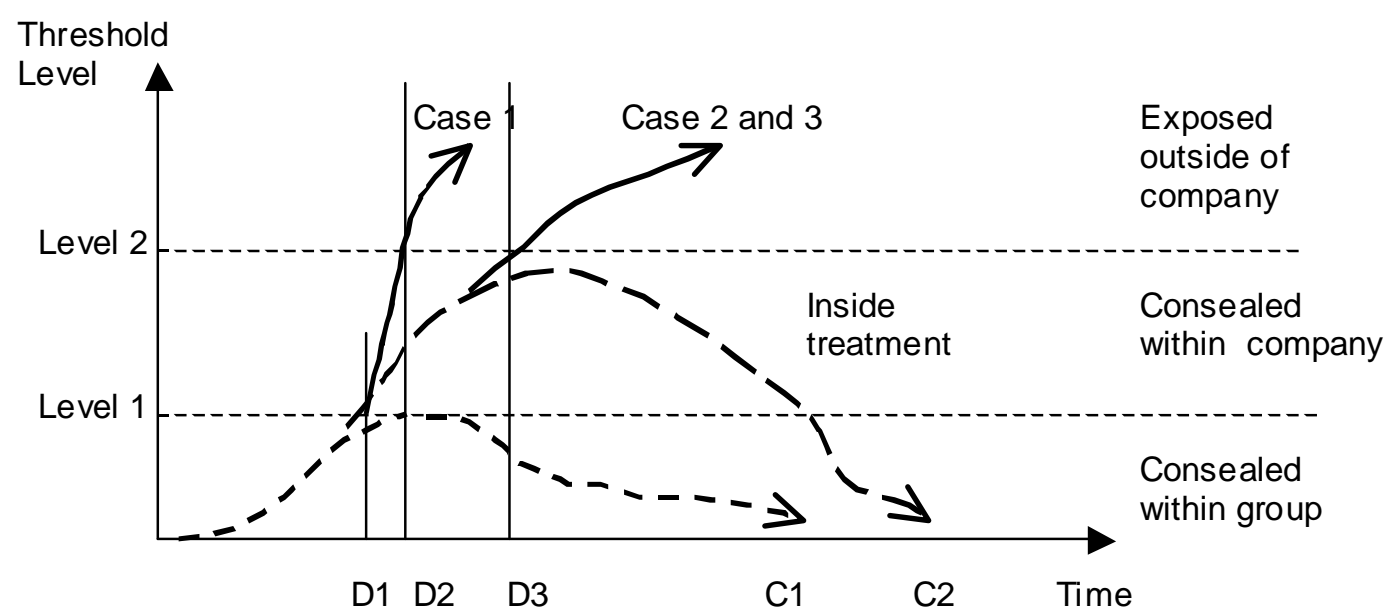

Figure 5 Typical Progressing of Ethics Problem 
Sakura Bank is one of the largest banks. Mitsui Marine Insurance is the third largest maritime insurance company. Mitsui Life Insurance is a medium sized company. These three companies belong to Mitsui Financial Group. They entered into business to form tie up with each other as a core of Mitsui Financial Group to cope effectively with financial deregulation.

\section{Case 6: Collaborated Parts Procurement Systems.}

In order to eliminate parts procurement cost, 182 electric machinery manufactures including Hitachi, Toshiba and Mitsubishi Electric are planning to build up electronic commerce systems on Internet. At the same time, they have decided to look for new suppliers not limited to the existing affiliated companies. The new systems will be completed in the coming May 2001.

\section{Case 7: Fujitsu and Canon Establish Internet Business}

Fujitsu and Canon established two joint investment companies in 2000. The objective of one company is to collect and distribute various contents to customers via Internet including pictures and texts. The other company is to set up parts procurement systems between "B to B" by applying electronic commerce.

\section{Learning from the Cases}

\section{Ethical Threshold Level of Organization}

Figure 5 shows some typical processing patterns obtained from the Case 1, 2 and 3. In vertical, there are two threshold levels. Level 1 corresponds to group-wide and Level 2 corresponds to company-wide. If some ethical problem occurs, the majority of group members will try to conceal the problem and cope with it, though it may adversely influence the customers or the environment. If they succeed in this, the ethical problem is successively concealed within the group. Consequently, the upper level management including CEO has no access to the information about the problem. If the group cannot solve the problem at D1, - i.e. it exceeds at the threshold value of Level 1, --it will be treated as a company-wide problem. However, it will be concealed as long as it can be treated within the company. If the problem exceeds Level 2, it sometimes becomes a serious problem enough to shake the very existence of the company. $n$ Case 1 , at the first stage the problem was concealed in the related divisions for maintaining their group reputation to the company.

Suddenly, the reputation collapsed by exposure from within. As a result, manager in charge was severely punished. In Case 2 and 3, both companies tried to conceal the problem by company-wide effort. The authorities attempted to contain the problem inside the company. However, once the defect exceeded Level 2, the defect was exposed suddenly to the outside. The motive of exposition in Case 2 was exposure from within, while in Case 3, the motive was complaining from customers who were poisoned. In any cases, if management is able to make a soft landing on $\mathrm{C} 1$ or $\mathrm{C} 2$, it brings honor to the management as well as to the members even if it will not be generally accepted by society today.

When problems are exposed to the outside, a person in charge will generally claim, "Though it may be morally at fault, we are not legally responsible." However, business ethic has become a matter of great importance in recent years. Many companies have been establishing moral standards. For example, Texas Instruments, Japan (hereafter, TI) organized "ethic office" composed of inspection committee in board of directors, TI ethic committee, TI ethic officers and contact persons in every country (Shimada, 2000).

\section{Strategic Alliance beyond Financial Groups}

Case 4 to case 7 is typical examples of strategic Alliance beyond the strong walls placed within great financial groups. Such a drastic change was unimaginable just few years ago. These companies cooperate each other in some fields, but they still compete fiercely in another market prances. The most serious problem rested in the difference of each organization's culture that lacked communication between each other.

\section{Improvement of Information sharing across boundaries}

From our study, these cases may be attributed to the information, taking place across the boundary as shown in Figure 4. Case 1 corresponds to stress "a" in Figure 4, while Case 2 to stress "b", and Case 3 to stress "c" respectively. Case 4, 5, 6 and 7 are examples of eliminating stress "d" and/or stress "e".

The key factor of these cases results from information sharing across the boundary between organizations. In Case 1, 2 and 3, there is a different tacit knowledge exists among the organizations that resulted from the lack of Type B sort of information sharing. 


\section{Using IT to Improve Communication}

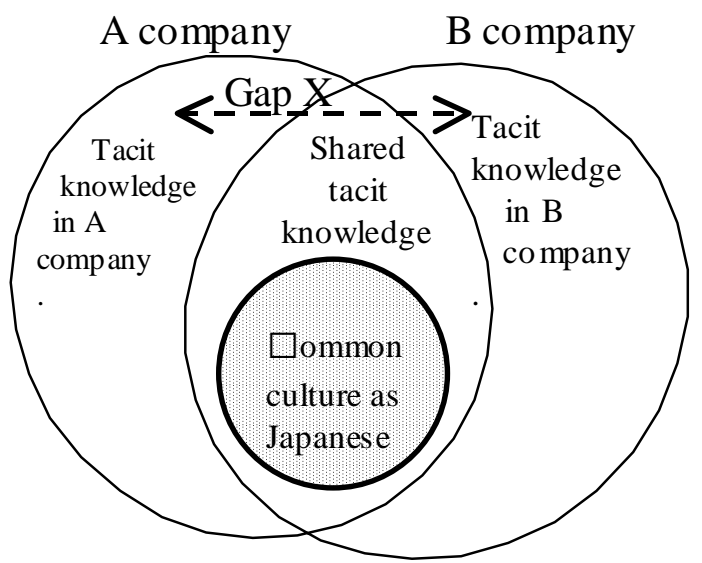

(a) Between Japanese organizations

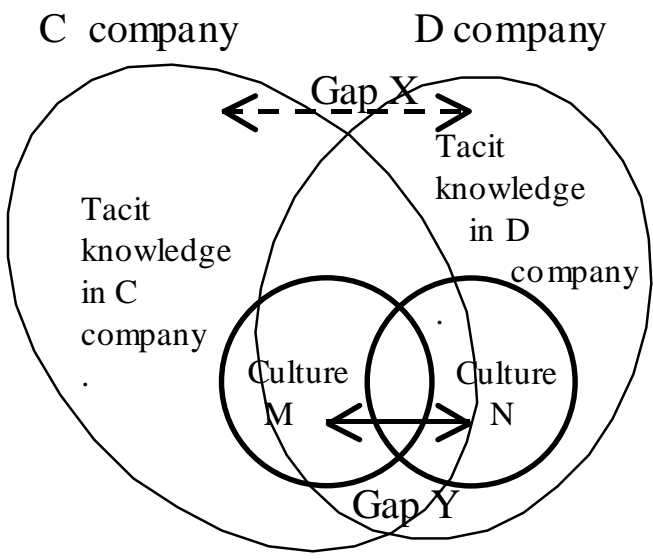

(b) Between foreign organizations

Figure 6 Communication gaps of Type B information

\section{Effectiveness of IT}

\section{Role of IT}

Robbson (1994) suggested the following five questions about the role IT does or IT can play, by applying Porter's model.

- (1) Can IT change the balance of power with suppliers?

- (2) Can IT build barrier to entry?

- (3) Can IT build in switching costs?

- (4) Can IT generate new products of services?

- (5) Can IT change the basis of competition?

Also, Robbson suggested that strategic potential for IT can be classified by the five forces; namely,

- (1) Avoid switching cost and backward integration,

- (2) Entry barriers and entry deterrents,

- (3) Switching cost and buyers selection,

- (4) Relative price-performance and product features,

- (5) New basis of competition and shared IT.

\section{IT for Type A Information}

As for sharing the Type A information, there is no greater difference occurs between companies in Japan and other countries, excluding some exceptions in small and medium-sized companies (hereafter, SMEs). Type A information will mainly be processed "in B," "B to B," "B to C" networks. As a result, even in Japanese companies, standardization and rationalization of business process have been remarkably accelerated. Consequently, even in Japa- nese companies, the Robbson's five questions have been achieved considerably.

Most of shared Type A information will mainly be generated from some routine transaction-processing systems. The other Type A sort of information will be retained in secret unless boundaries exist. If they share entire information, no boundary exists.

\section{IT for Type B Information}

On the other hand, Type B communication is questionable. We can see peculiar Japanese way of Type B communication that impedes mutual understanding between organizations, companies, etc. When Japanese Soccer Team won Saudi Arabia, Philippe Troussier, coach of Japanese Soccer Team said, "Each Japanese players is too weak to assert himself. At first, I tried to let them assert loudly. But, now, I believe Japanese mentality of amity will also flow into their ability in soccer." (Nikkei, 30 October 2000) This example shows the merit of the Japanese style but at the same time, it becomes a serous demerit for better communication. Figure 6 illustrates how these characteristics affect on communication. As the proverb says, "Actions speak louder than words", there are some common cultural traits between each Japanese company though in competition at they withdraw into their organization's own shell. Within the own shell, direct communication from mind to mind is more effectively performed.

Figure 6 (a) shows typical structure of tacit knowledge gap between "A" company and "B" company, although, as we mentioned before, there are hierarchy of organizations. Gap $\mathrm{X}$ in this figure represents the difference of tacit knowledge across the boundary of two companies where tacit knowl- 


\section{Hanaoka and Shimada}

edge refracts, reflects, diffused, attenuated and disturbed as shown in Figure 3. Both companies must broaden the area of "shared" tacit knowledge. At the same time, both companies must recognize and understand partner's organization culture by minimizing Gap X.

Figure 6 (b) illustrates communication gap between two companies of different countries, i.e., $\mathrm{M}$ and N. There are culture gap between the two countries illustrated. Gap Y. For example, one of the serious problems for most Japanese companies is lack of employee's skill in English. At present, the direct effectiveness of IT for filling the gap of Type B communication seems to have their limitations.

Although, as for Nonaka's knowledge conversion model, if Type A communication improved by IT, then indirectly, Type B communication will also be improved.

\section{IT in SMEs}

There are millions of SMEs in Japan. Some of them are energetic in spite of economic depression. In general, process of computerizing in such SMEs is still slow in progress. For examples, in the SMEs in Kanagawa Prefecture (30 miles south from Tokyo), computerized processing of Type A information remains at a $20 \%$ level. This means the majority of transaction in SMEs depends on the telephone, facsimile and postal mail (Hanaoka \& Shimada, 2000).

As for Nikkei, June 6 2000, three key words commonly characterized the strong venture businesses in Japan, i.e., "restrained," "steady" and "low technology." The report said that most Japanese ventures do shy away from competing with big businesses. Most of them will try to have predominant position over big businesses in their specific fields such as precision machinery, fondly, precise handicraft, specialized small market, etc. by their own tacit knowledge transmitted from person to person, which is based on empiricism. Here, IT does not always play a significant role in Japanese companies.

On the other hand, the report claims that most American venture businesses try to create new business models by actively applying the latest IT, and collect a large amount of raised funds from courageous investors who desire to challenge to the existing big businesses. Here, IT plays a significant role in creating new business opportunities.

\section{Findings}

\section{Information Sharing}

The survey shows that the information sharing in the typical Japanese companies are characterized as follows.
- (1) Every organization has its own culture and has its own tacit knowledge.

- (2) Employees feel security when they are involved in their organization.

- (3) There are firm boundaries between organizations.

- (4) Boundaries are stacked in hierarchy.

- (5) Boundaries impede sharing unprofitable information between each organization unless it remains at a lower than threshold level.

- (6) Explicit knowledge will transmit only within the organization.

- (7) Information across any boundary refracts, reflects or is diffuses by the difference of each organization's culture.

- (8) Information will be attenuated, disturbed and distorted by each organization's culture.

- (9) "Middle up down" decision-making process is still universally practiced in Japan.

\section{Utilization of IT}

The typical characteristics of IT utilization in Japanese companies are as follows.

- (1) Type A information sharing among organizations is making steady progress by utilizing IT, except most SMEs.

- (2) Type B information sharing among organization will be accelerated by e-mail, but they will try its utmost in keeping unprofitable information in secret.

\section{Conclusion}

This paper has proposed the structure of decision-making process and behavior of information across the boundary between organizations as existing in most Japanese companies. Generally, there are strong boundaries between Japanese organizations. As a result, the behavior of Type B information seems to be peculiar; each organization has its own tacit knowledge that transmits from experienced person in specific field to the next generation. In addition, "Middle up down" decision-making process is still in common, which is based on mutual agreement of member of a group or organization.

In recent years, even in Japan, the latest IT has been widely applied in many companies. As a result, computerization is extremely effective for sharing Type A information across the boundary of organizations and for speeding up the process of structural decision-making process. On the contrary, sharing Type B information cannot be improved by IT alone, because development of tacit knowledge depends on the characteristics of the organization's own culture. 


\section{Using IT to Improve Communication}

\section{References}

Abegglen, J. C., 1958, The Japanese Factory; Aspects of its Social Organization, The Free Press.

Abegglen, J. C., 1973, Management and Worker; The Japanese Solution, Sophia University.

BenDasan, I., 1972, About Japan Sect (Nihon-kyo ni tsuite), BungeiShunju (Written in Japanese).

Bignell, V., 1985, Understanding Systems Failure, The Open University, Manchester University Press.

Czinkota, M. R. \& Woronoff, J. 1991, Unlocking Japan's Markets, Probus Publishing

Hanaoka, S., \& Shimada, T., "Characterizing the Progress of Information Systems and Virtual Organization," Proceedings 1997 The Eight International Conference on Comparative Management, National Sun Yat-sen University, Taiwan, May 25-27.

Hanaoka, S., 1999, "A Study on the Framework of Managing Information Systems. Part 1." Keizaikei, Quarterly Journal of Economics, The Society of Economics of Kanto Gakuin University. (Written in Japanese)

Hanaoka, S., \& Shimada, T., 2000, "Utilizing Information Systems in Small and Medium Sized Enterprises in Japan," PACIS 2000 Conference Proceedings, Fourth Pacific Asia Conference on Information Systems PACSIS 2000 Hong Kong 1-3 June.

Hanaoka, S., 2000, "A Study on the Framework of Managing Information Systems. Part 2." Keizaikei, Quarterly Journal of Economics, No.202, The Society of Economics of Kanto Gakuin University. (Written in Japanese)

Hijikata, B., 1968, Principle of Ability and Dynamic Management (Nouryoku-Shugi to Doutai-Soshiki), Sangyo Nouritsu Tanki Daigaku. (Written in Japanese)

Imai, K., 1984, Information Network Society (Jouhou Network Shakai), Iwamami. (Written in Japanese)

Nonaka, I. \& Takeuchi, H, 1995, The Knowledge Creating Company; How Japanese Companies Create the Dynamics of Innovation, Oxford University.

Ouchi, W. G., 1981, Theory Z; How American Business can meet the Japanese Challenges, Wesley

Porter, M. E. \& Millar, V. E., 1985, "How Information gives you Competitive Advantage," Harvard Business Review Vol. 63 No. 4, Jul Aug.
Robbson, W., 1994, Strategic Management and Information Systems; An Integrated Approach, Pitman Publishing.

Shimada, T., 2000, "Texas Instrument, Japan," Hanaoka, S., et. al.. (eds.), Information Resources Strategy (Jouhou Shigen Kanri), Nikka Giren. (Written in Japanese)

Shimada, T. \& Hanaoka, S., 2000b, "An Empirical Study of Excellent Information System in Japanese Firms," Challenges of Information Technology Management in the 21st Century, 2000 Information Resources Management Association International Conference Anchorage, May 21-24.

Tapscott, D., 1996, The Digital Economy; Promise and Peril in the Age of Networked Intelligence, McGraw-Hill.

Vogel. E., E, 1979, Japan as Number One; Lessons for America, Harvard University Press.

Vogel, E. E., 1984, Comeback, Davis Britannica.

Yoshino, Y., 1968, Japan's Management System, MIT Press.

\section{Biography}

Sho Hanaoka is Professor of Management Information Systems at the Faculty of Economics, Kanto Gakuin University. He received his doctorate in philosophy from Tokyo Institute of Technology, and a master degree in geophysical prospecting from Kyoto University. His undergraduate degree is from the Department of technology, Tohoku University. His research interest include: nature of relationship between virtual organization and IS outsourcing, mechanism for generating consensus between the IS Division and the end users, and the development of measures for evaluating IS acceptance by both IS staff and the end users.

Tatsumi Shimada is Professor of Engineering at the Tokyo Metropolitan Institute of Technology. He received his Doctorate in Business Administration from the Osaka City University. His research interest include, IS outsourcing, impact of IT on organizations, and the Comparative study of IS implementation in local government and private firms. 